\title{
MiR-18a and miR-18b are expressed in the stroma of oestrogen receptor alpha negative breast cancers
}

Nina Gran Egeland ${ }^{1,2+}{ }^{,}$Kristin Jonsdottir $^{1 *+}{ }^{2}$, Miriam Ragle Aure ${ }^{3}$, Kristine Sahlberg ${ }^{3,4}$, Vessela N. Kristensen ${ }^{3,5}$, Deirdre Cronin-Fenton ${ }^{6}$, Ivar Skaland ${ }^{1}$, Einar Gudlaugsson ${ }^{1}$, Jan P. A. Baak ${ }^{1,7}$ and Emiel A. M. Janssen ${ }^{1,2}$

\begin{abstract}
Background: Previously, we have shown that miR-18a and miR-18b gene expression strongly correlates with high proliferation, oestrogen receptor -negativity $\left(E R^{-}\right)$, cytokeratin 5/6 positivity and basal-like features of breast cancer.

Methods: We investigated the expression and localization of miR-18a and -18b in formalin fixed paraffin embedded (FFPE) tissue from lymph node negative breast cancers $(n=40)$, by chromogenic in situ hybridization (CISH). The expression level and in situ localization of miR-18a and -18b was assessed with respect to the presence of tumour infiltrating lymphocytes (TILs) and immunohistochemical markers for ER, CD4, CD8, CD20, CD68, CD138, PAX5 and actin. Furthermore, in two independent breast cancer cohorts (94 and 377 patients) the correlation between miR-18a and -18b expression and the relative quantification of 22 immune cell types obtained from the CIBERSORT tool was assessed.

Results: CISH demonstrated distinct and specific cytoplasmic staining for both miR-18a and miR-18b, particularly in the intratumoural stroma and the stroma surrounding the tumour margin. Staining by immunohistochemistry revealed some degree of overlap of miR-18a and -18b with CD68 (monocytes/macrophages), CD138 (plasma cells) and the presence of high percentages of TILs. CIBERSORT analysis showed a strong correlation between M1macrophages and CD4+ memory activated T-cells with mir-18a and -18b.

Conclusions: Our study demonstrates that miR-18a and miR-18b expression is associated with ER- breast tumours that display a high degree of inflammation. This expression is potentially associated specifically with macrophages. These results suggest that miR-18a and miR-18b may play a role in the systemic immunological response in ER ${ }^{-}$ tumours.
\end{abstract}

Keywords: Breast cancer, microRNA, In situ hybridization, Tumour microenvironment, Macrophages, Tumour associated macrophages (TAM)

\footnotetext{
* Correspondence: kristin.jonsdottir@sus.no

${ }^{\dagger}$ Nina Gran Egeland and Kristin Jonsdottir contributed equally to this work.

${ }^{1}$ Department of Pathology, Stavanger University Hospital, Box 8100, 4068 Stavanger, Norway

Full list of author information is available at the end of the article
}

(C) The Author(s). 2020 Open Access This article is licensed under a Creative Commons Attribution 4.0 International License, which permits use, sharing, adaptation, distribution and reproduction in any medium or format, as long as you give appropriate credit to the original author(s) and the source, provide a link to the Creative Commons licence, and indicate if changes were made. The images or other third party material in this article are included in the article's Creative Commons licence, unless indicated otherwise in a credit line to the material. If material is not included in the article's Creative Commons licence and your intended use is not permitted by statutory regulation or exceeds the permitted use, you will need to obtain permission directly from the copyright holder. To view a copy of this licence, visit http://creativecommons.org/licenses/by/4.0/. The Creative Commons Public Domain Dedication waiver (http://creativecommons.org/publicdomain/zero/1.0/) applies to the data made available in this article, unless otherwise stated in a credit line to the data. 


\section{Background}

Oestrogen receptor alpha (ER) expression is the most widely used predictive biomarker for breast cancer. Most patients with ER positive $\left(\mathrm{ER}^{+}\right)$tumours receive adjuvant endocrine therapy and have a good prognosis. In contrast, ER negativity $\left(\mathrm{ER}^{-}\right)$is found in roughly $15 \%[1,2]$ of all breast cancers, and these tumours are often associated with high proliferation and a relatively poor prognosis. Additionally, there are few effective adjuvant therapy options for this group and for the so-called triple-negative (TNP) breast cancers that lack expression of ER, progesterone receptor (PR) and human epidermal growth factor receptor 2 (HER2). Therefore, there is a need for identifying new prognostic biomarkers and more specific, novel targets for therapy. Also, more knowledge of the biology of these tumours is necessary to improve the prognosis of patients with $\mathrm{ER}^{-}$breast cancer.

MicroRNAs are defined as short non-coding RNA molecules, of which the mature form is about 22 nucleotides in length. Each microRNA is complementary or partially complementary to several mRNA molecules, and its main function is to post-transcriptionally downregulate gene expression by either binding directly to its mRNA target, or by cleaving target mRNA by binding to its 3'-untranslated region (UTR) [3]. Some microRNAs are predicted to bind several hundred gene targets (mRNAs), and different microRNAs can also target the same gene [4]. Studies of mammalian cells have shown that microRNAs are one of the largest groups of translational regulators in human cells [3], and they are known to play a significant role in many cellular functions [5] and in a number of diseases, including cancer $[6,7]$.

Previously, we have shown that gene expression of miR-18a and miR-18b is strongly correlated with high proliferation, $\mathrm{ER}^{-}$and cytokeratin 5 and -6 positivity $(\mathrm{CK} 5 / 6+)$ [8, 9]. MiR-18a belongs to the miR-17 92 cluster located on chromosome 13 , while miR-18b belongs to the miR-106a $~ 363$ cluster located on chromosome $\mathrm{X}[10,11]$. MiR-18a and miR-18b, and their cluster members, are mostly described as oncomicroRNAs because they show higher expression in many different tumour types, and especially in more advanced tumours [10, 12]. Several studies have shown that the expression of miR-18a and miR-18b is associated with ER- status [8, 13-15], and research suggests that ER can be a direct target of miR-18a [13, 16, 17].

Besides cancer cells, tumour tissue is made up of stromal cells such as fibroblasts, adipocytes, endothelial cells and various immune cells. The tumour microenvironment (TME) contains a heterogeneous collection of immune cell types, such as T-cells and B-cells, natural killer cells, macrophages, dendritic cells and neutrophils (reviewed in $[18,19]$ ). MicroRNAs are also involved in the interplay between cancer and immune cells [20]. It has been reported that microRNAs take part in cell-cell signalling and communication between tumour cells and the surrounding microenvironment [21], by means of paracrine signalling $[22,23]$ and release of extracellular vesicles [24], especially exosomes [25, 26]. It is now recognized that the TME plays a critical role in both initiation and progression of cancer, and thus has prognostic potential. The cells within the TME take part in bidirectional cross-talk and interactions with the malignant cells, and they can have pro- or anti-tumour functions, depending on the type of immune cells involved [27, 28]. Cancer-associated immune cells also play a role in treatment response [26], and may have therapeutic potential. Several studies have shown the prognostic relevance of tumour-infiltrating lymphocytes (TILs) in breast cancer, especially in the HER2-positive and triple-negative subtypes (reviewed in [29]).

Here, we applied chromogenic in situ hybridisation (CISH) and immunohistochemistry (IHC), to locate and identify which cells express miR-18a and miR-18b in breast cancer. To further investigate the origin of these cells, we applied the analytical tool CIBERSORT [30] that uses gene expression data from bulk tumour to deconvolute expression and derive relative quantification of hematopoietic cell populations, to assess which cell types miR-18a and miR-18b are associated with.

\section{Methods}

\section{Patients}

This study was approved by the Norwegian Regional Committees for Medical and Health Research Ethics (REC). All patients were treated according to the national guidelines of the Norwegian Breast Cancer Group (NBCG) at the time of diagnosis.

Stavanger cohort: Breast cancer patients diagnosed with first onset invasive operable $\left(\mathrm{T}_{1,2} \mathrm{~N}_{0} \mathrm{M}_{0}\right)$ lymph node negative breast cancer at the Stavanger University Hospital between January 1, 1993 and December 31, 1998. From this Stavanger cohort, several sub-cohorts have been used in the present study: 1) A total of 94 lymph node negative breast cancer patients from previous studies [9, 31] with complete mRNA- and microRNA expression data, hereafter called the Stavanger array-cohort, were included for correlation analysis between CIBERSORT output (based on mRNA expression) and $\mathrm{miR}-18 \mathrm{a} / \mathrm{miR}-18 \mathrm{~b}$ expression. 2) We analysed TILs in 204 samples (from our previous study [8]), and correlated this with our previous expression data of miR-18a and $-18 \mathrm{~b}$ (measured by quantitative real-time PCR (qPCR)), and grouped the patients based on ER status and high vs low TILs. This sub-cohort will here onwards be referred to as the Stavanger qPCR-cohort. 
CISH cohort: Based on our previous findings of higher amounts of miR-18a and $-18 \mathrm{~b}$ in $\mathrm{ER}^{-}$breast cancer, a total of 40 samples from the Stavanger qPCR-cohort [8] described above were selected for $\mathrm{CISH}$ as follows: 20 tumours classified as $\mathrm{ER}^{+}$with low expression of miR$18 \mathrm{a}$ and miR-18b (as measured by qPCR), and $20 \mathrm{tu}-$ mours classified as $\mathrm{ER}^{-}$with high expression of miR-18a and miR-18b (as measured by qPCR). We analysed TILs in the 40 tumours and correlated this with the CISH expression of miR-18a and $-18 \mathrm{~b}$. For the patients' clinical characteristics, please see additional files (Additional file 1, S1 Table). Furthermore, CISH was performed also on lymph nodes histologically negative for tumour cells from two $\mathrm{ER}^{-}$patients, as well as on lymph nodes histologically positive for metastasis from four $\mathrm{ER}^{+}$or $\mathrm{ER}^{-}$patients. Also, CISH was performed on a test block consisting of several tumour types from different patients, and on a lymph node diagnosed as reactive lymphadenitis from the neck (this patient had no history of breast cancer and had no other clinical symptoms).

Oslo2 cohort: a multicentre study of breast cancer patients with primary operable breast cancers consecutively enrolled from hospitals in the Oslo region from 2006 until today. Patients were included at the time of primary surgery. Tumours from the Oslo 2 study $(n=308)$ and from a similar study conducted at the Akershus University Hospital (Ahus), Norway, from 2003 to 2010 $(n=69)$ were selected for CIBERSORT analyses and correlation to miRNA expression. Total RNA was isolated from fresh-frozen (Oslo2) or RNAlater ${ }^{\circ}$ (Ahus) material using TRIzol ${ }^{\mathrm{TM}}$, and microRNA expression data for altogether 377 tumours were correlated with matching CIBERSORT output based on mRNA expression [32, 33] using Agilent microarrays (Agilent Technologies, Santa Clara, CA, USA). For CIBERSORT analyses, both lymph node positive and -negative patients were included $(n=$ 377).

\section{Histopathology and immunohistochemistry}

The tumour tissue was fixed in buffered $4 \%$ formaldehyde and then embedded in paraffin. Sections were cut at a thickness of four $\mu \mathrm{m}$ and stained with haematoxylin, erythrosine and saffron. The histological type was assessed according to the World Health Organization criteria [34] and the tumour grade was assessed according to the Nottingham grading system [35]. ER was scored positive if $\geq 1 \%$ of tumour cells exhibited nuclear staining, while all others were scored negative. All sections were scored independently by two experts.

IHC was used to detect ER, CD4, CD8, CD20, CD68, CD138, PAX5 and actin. These methods were based on DAKO technology as described previously [36]. In brief, FFPE-sections of $2 \mu \mathrm{m}$ thickness were mounted onto Superfrost Plus slides (Menzel, Braunschweig, Germany). Antigens were retrieved with a highly stabilized retrieval system (ImmunoPrep; Instrumec, Oslo, Norway) using $10 \mathrm{mM}$ TRIS/1 mM EDTA (pH 9.0) as the retrieval buffer. Slides for actin staining were not treated with retrieval buffer. Sections were heated for $3 \mathrm{~min}$ at $110^{\circ} \mathrm{C}$ followed by $10 \mathrm{~min}$ at $95^{\circ} \mathrm{C}$ then cooled to $20^{\circ} \mathrm{C}$. The sections were incubated with monoclonal antibody at the dilutions stated in Table 1.

\section{MicroRNA and mRNA expression profiling}

The microRNA and mRNA expression profiling data from fresh-frozen tumour tissue used in this analysis have been published previously [9, 31-33].

\section{Chromogenic in situ hybridization}

CISH was performed on FFPE tissue using miRCURY LNA $^{\mathrm{TM}}$ microRNA ISH optimization kit (FFPE) v1.3 (Exiqon, Vedbaek, Denmark). The manufacturer's protocol was followed with some minor changes. Briefly, $5 \mu \mathrm{m}$ thick paraffin sections were mounted on Superfrost ${ }^{\mathrm{TM}}$ Plus glass slides and incubated overnight at $55^{\circ} \mathrm{C}$. The slides were deparaffinised with xylene and alcohol dilutions. The slides were then washed in PBS for $4 \mathrm{~min}$, digested with $15 \mu \mathrm{g} / \mathrm{ml}$ of Proteinase $\mathrm{K}$ at $37^{\circ} \mathrm{C}$ for 30 min, and washed in PBS before dehydration through a series of graded alcohol. The slides were hybridized with double DIG labelled Locked Nucleic Acid $^{\mathrm{TM}}\left(\mathrm{LNA}^{\mathrm{TM}}\right)$ (Exiqon) probes at $55^{\circ} \mathrm{C}$ for $1 \mathrm{~h}$ (see Additional file 2, S2

Table 1 Monoclonal antibodies used in IHC staining

\begin{tabular}{lllll}
\hline Antibody & Clone & Concentration & Target cells & Company \\
\hline ER & SP1 & $1: 400$ & Epithelial cells & Thermo Scientific, Waltham, USA \\
CD4 & 4 B12 & $1: 100$ & CD4+ T-cells & Novocastra, Newcastle Upon Tyne, UK \\
CD8 & C8/144B & $1: 50$ & CD8+ T-cells & DAKO, Agilent Technologies, Santa Clara, CA, USA \\
CD20 & L26 & $1: 1000$ & B-cells, neoplasms of B-cells & DAKO \\
CD68 & PG-M1 & $1: 400$ & B-cells, macrophages, histiocytes, dendritic cells, NK cells & DAKO \\
CD138 & B-A38 & $1: 50$ & Plasma cells and some epithelial cells & AbD Serotec (BioRad), Kidlington, UK \\
PAX5 & 24 & $1: 100$ & B-cells & BD Biosciences, San Diego, USA \\
Actin & 1A4 & $1: 300$ & Fibroblasts & DAKO
\end{tabular}

Antibody, clone, concentrations used, Target cells and company of the antibodies used in IHC staining 
Table). The probe concentrations were $80 \mathrm{nM}$ for the hsa-miR-18a-5p, hsa-miR-18b-5p and scramble probe, and $2.0 \mathrm{nM}$ for the positive control probe U6. After hybridization the slides were washed consecutively with 5x SSC, 1x SSC and 0.2x SSC (Sigma Aldrich, St. Louis, $\mathrm{MO}, \mathrm{USA}$ ) at $50{ }^{\circ} \mathrm{C}$ for a total of $30 \mathrm{~min}$. Then the slides were incubated with blocking solution containing $1 \mathrm{x}$ Maleic acid buffer (Roche, Mannheim, Germany), 10x Blocking Solution (Roche) and 2\% sheep serum (Jackson Immunoresearch, Suffolk, UK) for $15 \mathrm{~min}$, before application of 1:800 dilution of sheep anti-DIG alkaline phosphatase (Roche) at $30{ }^{\circ} \mathrm{C}$ for $30 \mathrm{~min}$. The slides were then washed with $1 \%$ Tween-PBS for $3 \times 3 \mathrm{~min}$, before they were incubated with AP substrate containing NBT/ BCIP (Roche) at $30{ }^{\circ} \mathrm{C}$ for $110 \mathrm{~min}$. This allowed for visualization of antibody signals by NBT-BCIP. Sections were then washed twice for $5 \mathrm{~min}$ in KTBT buffer (50 $\mathrm{mM}$ Tris- $\mathrm{HCl}, 150 \mathrm{mM} \mathrm{NaCl}, 10 \mathrm{mM} \mathrm{KCl}$ ), before being rinsed in ultrapure water $2 \times 1 \mathrm{~min}$. For nuclear counterstaining, the sections were immersed in Nuclear Fast Red (Sigma Aldrich, St. Louis, MI, USA) for $3 \mathrm{~min}$, and then rinsed in running tap water for $5 \mathrm{~min}$. Finally, the sections were dehydrated through a series of graded alcohol, and subsequently mounted by Histokitt mounting medium (VWR, Oslo, Norway).

\section{Quantification of miR-18a and miR-18b}

Specific staining for both microRNAs was observed as a dark blue colour from the NBT/BCIP precipitation. The sections were examined by light microscopy, and positive miR-18a and miR-18b staining was quantified by cell counting in two selected areas with the highest number of positive cells within the tumour area. In these hotspot areas all positive cells were counted at $40 \mathrm{x}$ in an area of $1.59 \mathrm{~mm}^{2}$. The two areas were scored separately, and the sum of both made up the final score for each slide. Dark blue cells without a visible nucleus or distinct cell membrane were excluded, as were light purple cells. Sections with negative U6 staining or slides in which a substantial amount of material was lost during the experimental treatment, were also excluded from the study $(n=4)$.

\section{Scoring of lymphocyte infiltration}

The variable degree of lymphocytic infiltration in HEstained tissue sections was evaluated semi-quantitatively. First, the sections were assessed according to the presence or absence of stromal tumour infiltrating lymphocytes (sTILs). Second, the relative amount of TILs in the tumour stroma area was assessed according to the method described by Denkert et al. [37]. The degree of infiltration was scored in the range of $0-100 \%$.

\section{CIBERSORT analysis}

CIBERSORT (Cell-type Identification By Estimating Relative Subsets Of RNA Transcripts) is a computational framework, that on the background of gene expression data and a signature gene file quantifies the relative or absolute levels of member cell types in a mixed cell population [30]. We ran CIBERSORT using the LM22 signature gene file which provides the relative abundance of 22 distinct mature human hematopoietic populations. The mRNA expression data from the Stavanger array [31] $(n=94)$ and Oslo2 [32] $(n=377)$ cohorts were used and the maximum number of permutations $(n=$ 1000) were chosen. The output from CIBERSORT was a matrix with quantification of the 22 cell types for each tumour sample.

\section{Statistical analyses}

Statistical analyses were conducted using the software program SPSS (version 20.0, SPSS, Chicago, IL, USA) and $\mathrm{R}$ [38]. Differences between patient groups were tested using an independent T-test and correlations between different expression levels were done using both Pearson's and Spearman's correlation. To assess the association of cell type composition with miR-18a and $-18 b$, we calculated the Spearman correlation coefficient between miR-18a and $-18 \mathrm{~b}$ expression and the CIBERSORT-based quantification of 22 hematopoietic cell types. Finally, the correlations were ranked in decreasing order.

\section{Results}

\section{Expression of miR-18a and miR-18b in FFPE tissue}

Detection of miR-18a and miR-18b by CISH in FFPE tissue from breast cancer patients resulted in strong and specific cytoplasmic staining in cells in the intratumoural stroma (Fig. 1) or stroma surrounding the tumour margin (Fig. 2). Both microRNAs were typically found in round shaped cells located within the tumour stroma, although some stained cells were more elongated and outstretched (Fig. 2). Little or no expression was found within the epithelial tumour cells or in cells further (> $0.5 \mathrm{~mm}$ ) away from the tumour area (Figs. 2 and 3). As expected based on our selection criteria, miR-18a and miR-18b had a significantly lower expression level in $\mathrm{ER}^{+}$tumours in comparison to $\mathrm{ER}^{-}$tumours (Independent T-test, $P<0.001$ for miR-18a and $P=0.002$ for miR18b) (Figs. 3, 4, and Table 2). The expression levels of miR-18a and miR-18b, as measured by CISH-expression levels, showed a strong correlation (Pearson's correlation coefficient of $0.85 P<0.001)$. Furthermore, these CISHexpression levels correlated well with those measured by qPCR in our previous study [8], for both miR-18a ( $\mathrm{r}=$ 0.75 Spearman's rho test $P<0.001)$ and for miR-18b $(r=$ $0.64, P<0.001)$. 


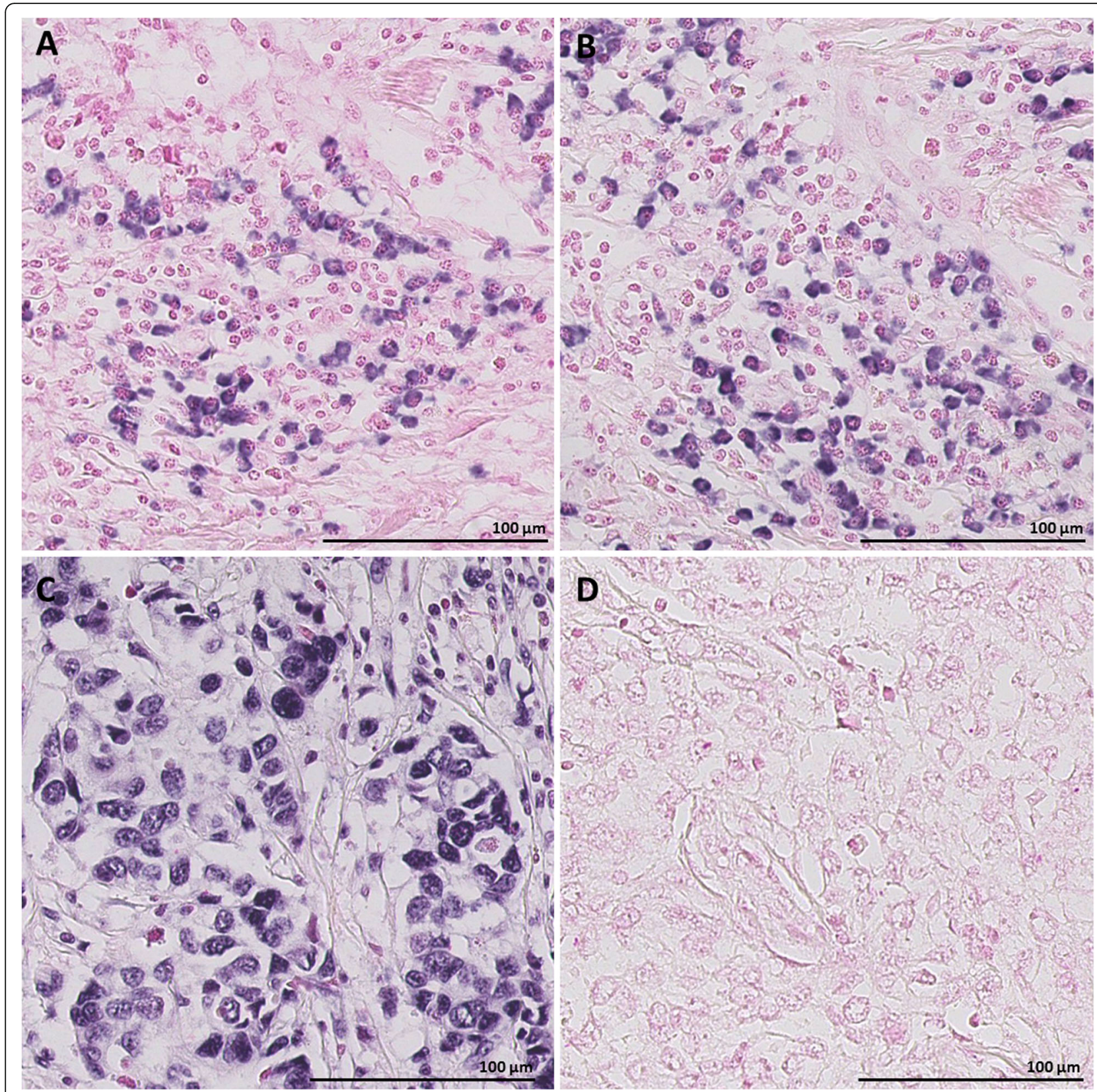

Fig. 1 40x magnification illustrating representative CISH staining with: a) LNA 5'-3'DIG hsa (80 nM) miR-18a probe showing strong and specific staining in stroma, b) LNA 5'-3'DIG hsa (80 nM) miR18-b probe showing strong and specific staining in stroma, c) U6 snRNA positive control probe showing overall nuclear staining, and d) negative probe (scrambled) probe with no hybridization signal. Scale bar $100 \mu \mathrm{m}$

\section{MiR-18a and miR-18b expression pattern in relation to immunohistochemical markers}

Although a strong and specific staining method was established, CISH has its limitations. Assessing the CISH slides only, pathologists were in doubt of the cell type that showed positive miR-18a and miR-18b expression. In an attempt to identify the cell type, we performed IHC on serial sections of the same breast tumours, and the corresponding lymph node samples. The following
IHC-markers were used: CD4, CD8, CD20, CD68, CD138, PAX5 and actin (Table 1).

A comparison between the different IHC stains and the CISH results for miR-18a and miR-18b showed some overlap with the expression of CD68 (monocytes/macrophages), CD138 (plasma cells) and actin (smooth muscle), although a complete match was not observed (Fig. 5). Actin staining identified fibroblast cells which were mostly oblong and outstretched, and since miR-18a and miR-18b were mainly expressed in round shaped 


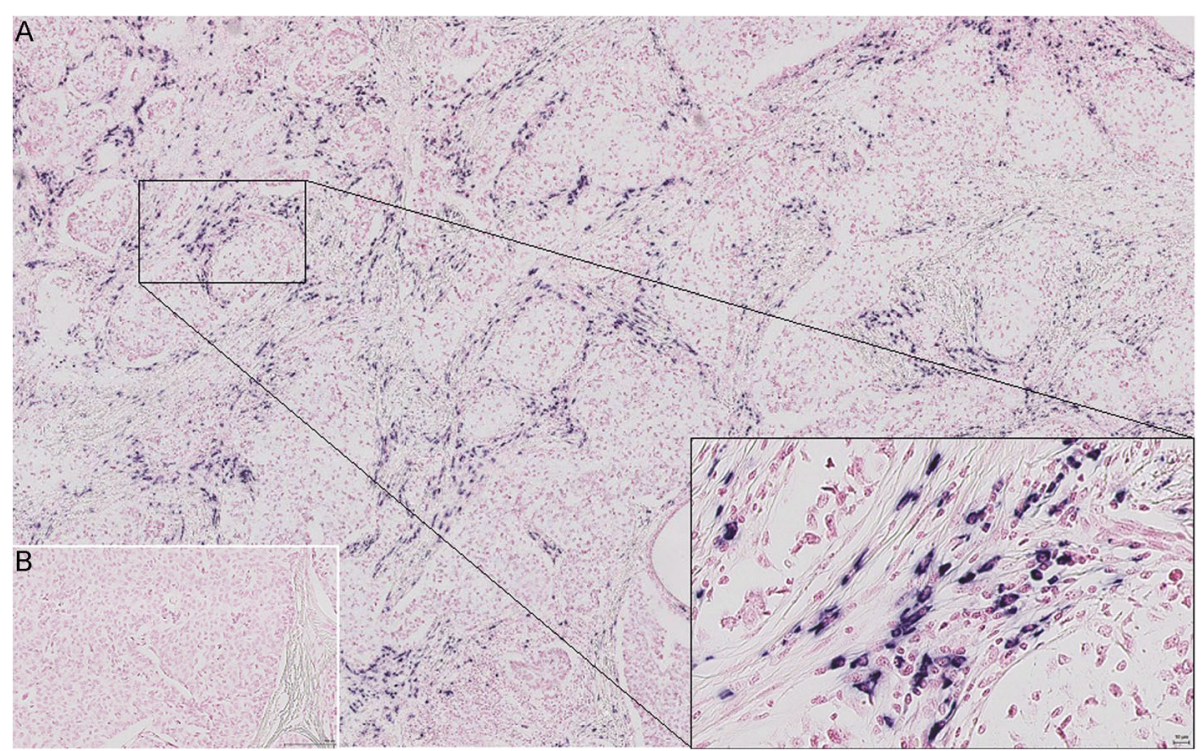

Fig. 2 Representative miR-18b CISH expression in an $E R^{-}$breast tumour (sample id: $20 \mathrm{ER}^{-}$in Table 2). a) Specific blue (NBT/BCIP) staining for LNA 5'-3'DIG hsa miR-18b (80 nM) probe. b) Negative control, i.e. staining with an LNA 5’-DIG scrambled probe ( $80 \mathrm{nM}$ )

cells, we hypothesized that the miR-18a and miR-18b positive cells are more likely to be associated with cells of lymphoid or myeloid origin.

Based on this we also stained lymph nodes from breast cancer patients both positive and negative for cancer cells (based upon histology from HE-slides), for the same IHC-markers as mentioned above, as well as for miR$18 \mathrm{a}$ and miR-18b. In the lymph nodes containing tumour cells, all the miR-18a- and miR-18b-positive cells were localized close to or in between the tumour cells (Fig. 6), thus following the pattern we observed in the primary tumours (for comparison with corresponding primary tumour, see Additional file 3, S1 Fig). This seemed especially true in patients with $\mathrm{ER}^{-}$tumours (ER tumour in Fig. 6, an $\mathrm{ER}^{+}$tumour in Additional file 4, S2 Fig). For the IHC markers, only the expression patterns for CD68 and CD138 showed some similarity with miR-18a and miR-18b expression, both in location and the shape and size of the positively stained cells (Fig. 6). Lymph nodes from breast cancer patients without tumour cells had a much more scattered staining pattern for miR-18a and miR-18b, with few positive cells and more stained cells in germinal centres. These results suggest that the miR-18a and miR-18b-expressing cells could be part of an immune response directed towards the tumour, and more specifically towards $\mathrm{ER}^{-}$tumour cells.

To investigate whether this reaction was cancer specific, we also analysed lymph nodes from patients with non-malignant disease, here in a case of reactive lymphadenitis (Fig. 7). In these non-malignant reactive lymph nodes miR-18a and $-18 \mathrm{~b}$ staining was mostly observed in the germinal centres. This, was in contrast with our observation in lymph nodes containing cancer cells where no staining was observed in the germinal centres. Again, comparison with the staining patterns for the IHC markers showed only partial overlap with CD68 and CD138 (Fig. 7).

\section{MiR-18a and miR-18b expression pattern in relation to tumour infiltrating lymphocytes}

Measurement of TILs in the $40 \mathrm{ER}^{+}$and $\mathrm{ER}^{-}$tumour tissues showed that the $E^{-}$tumours had a significantly higher number of TILs (Independent T-test, $P=0.0001$, boxplot in Fig. 8). As such we analysed TILs in 204 samples from our previous study [8], and compared it with the expression of miR-18a and $-18 \mathrm{~b}$ (measured by qPCR). Patients were also grouped based on ER status and high vs low TILs (Additional file 5, S3 Fig). Although not significant, a difference was observed between $\mathrm{ER}^{-} /$high TILs versus $\mathrm{ER}^{-} /$low TILs for both microRNAs. Additionally, the $\mathrm{ER}^{-}$with high TILs had significantly $(P<0.001)$ higher expression of miR-18a and miR-18b, than the $\mathrm{ER}^{+}$patients with high TILs (see boxplot in Additional file 5, S3 Fig). Again, this suggests that miR-18a and miR-18b expression is related to TILs and $\mathrm{ER}^{-}$cancers. Furthermore, miR-18a and $-18 \mathrm{~b}$ expression was also found in the stroma of both pancreatic cancer, and lung cancer tissue (Additional file 6, S4 Fig).

\section{MiR-18a and miR-18b expression and CIBERSORT}

To address the heterogeneity of immune cells in bulk tumour tissue, and to further investigate which type of cells express miR-18a and/or miR-18b, we used 


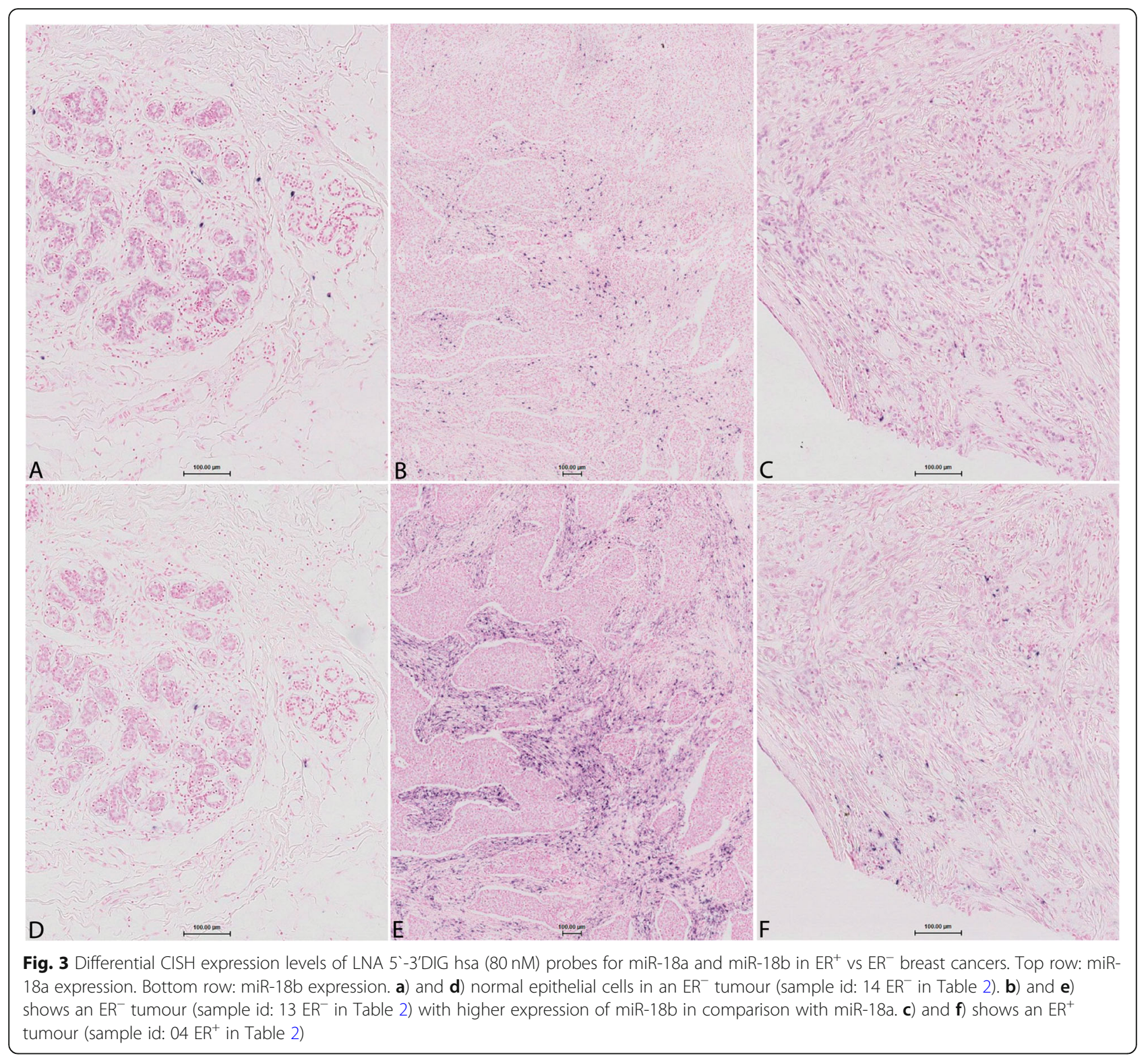

CIBERSORT [30] to characterize the cell composition of the bulk tumour tissue from which mRNA and miRNA was isolated. The output from CIBERSORT is a matrix of quantification levels of each of 22 immune cell types for each tumour. For each cell type, we took the vector of relative or absolute levels for all tumours and then compared this with the expression of miR-18a and miR$18 \mathrm{~b}$ for the same tumours. The resulting Spearman's Rho correlation coefficients are shown in the attached Table 3. For both relative and absolute assessment, the "M1 macrophages" cell type had the highest and most significant correlation in the Stavanger data. The cell type with the second highest correlation was "memory activated CD4+ T-cells". For the Oslo2 cohort, the latter cell type showed the highest positive correlation and the
"M1 macrophages" showed the second highest correlation (Table 3).

\section{Discussion}

High expression of miR-18a and miR-18b is known to be associated with $\mathrm{ER}^{-}$breast cancer, high proliferation and worse prognosis $[8,39]$. However, the role and function of these two microRNAs is not well understood. Our current in situ localisation shows that miR-18a and miR-18b are specifically expressed in the intratumoural stroma and in the stroma directly surrounding $\mathrm{ER}^{-}$tumours with a high degree of TILs. Additionally, the current study demonstrates the specificity of our $\mathrm{CISH}$ protocol, and subsequently confirms our previous qPCR 

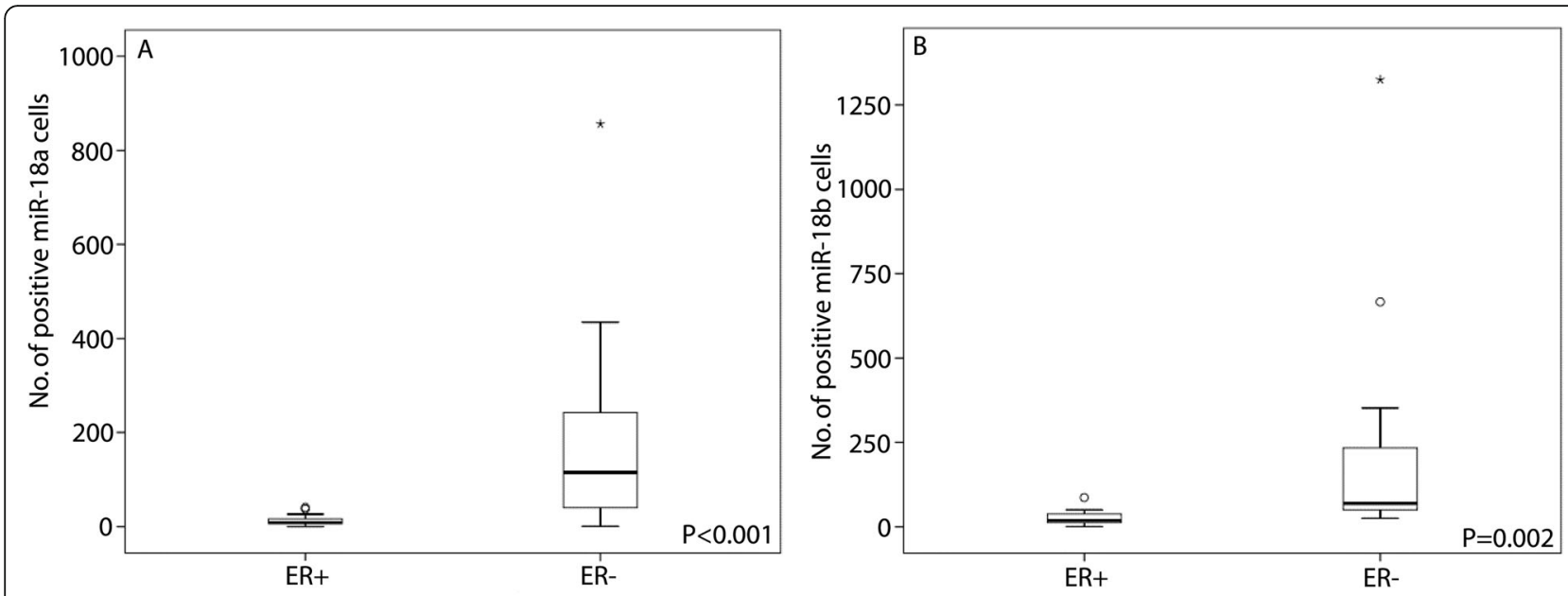

Fig. 4 Boxplot of CISH expression quantification, as measured by counting the number of positively stained cells in the $n=20 E R^{+}$vs the $n=20$ $E^{-}$breast cancers of $\left.\mathbf{a}\right)$ miR-18a and $\mathbf{b}$ ) miR-18b. Central line in boxes represent the median value, boundaries of boxes represent the interquartile range and ends of whiskers represent the minimum and maximum values, excluding outliers. $P$-values were obtained using independent T-test

results that miR-18a and miR-18b are highly expressed in $\mathrm{ER}^{-}$, and low in $\mathrm{ER}^{+}$breast cancers $[8,9]$.

Few studies have evaluated miR-18a or miR-18b expression patterns in cancer tissue using $\mathrm{CISH}$, and only Guo

Table 2 Quantification of cells positive for CISH expression of miR-18a and miR-18b

\begin{tabular}{|c|c|c|c|c|c|}
\hline \# / ER-status & miR-18a & miR-18b & \# / ER-status & miR-18a & miR-18b \\
\hline 01 ER- & 13 & 26 & $01 \mathrm{ER}+$ & 0 & 1 \\
\hline 02 ER- & 87 & 35 & $02 \mathrm{ER}+$ & 11 & 6 \\
\hline 03 ER- & 309 & 41 & $03 \mathrm{ER}+$ & 4 & 7 \\
\hline 04 ER- & 11 & 46 & $04 \mathrm{ER}+$ & 9 & 10 \\
\hline 05 ER- & 42 & 48 & $05 \mathrm{ER}+$ & 9 & 12 \\
\hline 06 ER- & 29 & 54 & $06 \mathrm{ER}+$ & 7 & 14 \\
\hline 07 ER- & 82 & 57 & $07 \mathrm{ER}+$ & 27 & 15 \\
\hline 08 ER- & 150 & 57 & $08 \mathrm{ER}+$ & 8 & 16 \\
\hline 09 ER- & 99 & 60 & $09 \mathrm{ER}+$ & 14 & 16 \\
\hline 10 ER- & 211 & 63 & $10 \mathrm{ER}+$ & 1 & 18 \\
\hline 11 ER- & 76 & 75 & $11 \mathrm{ER}+$ & 9 & 20 \\
\hline 12 ER- & 1 & 83 & $12 \mathrm{ER}+$ & 8 & 26 \\
\hline 13 ER- & 39 & 131 & $13 \mathrm{ER}+$ & 13 & 31 \\
\hline 14 ER- & 257 & 182 & $14 \mathrm{ER}+$ & 19 & 31 \\
\hline 15 ER- & 227 & 211 & $15 \mathrm{ER}+$ & 5 & 34 \\
\hline 16 ER- & 435 & 257 & $16 \mathrm{ER}+$ & 7 & 43 \\
\hline 17 ER- & 262 & 309 & $17 \mathrm{ER}+$ & 14 & 44 \\
\hline $18 \mathrm{ER}-$ & 131 & 352 & $18 \mathrm{ER}+$ & 21 & 48 \\
\hline 19 ER- & 209 & 666 & $19 \mathrm{ER}+$ & 38 & 51 \\
\hline 20 ER- & 856 & 1325 & $20 \mathrm{ER}+$ & 41 & 86 \\
\hline
\end{tabular}

Quantification of miR-18a and miR-18b expression, visualised by CISH, in 20 ER-positive and 20 ER-negative breast cancer tumours, sorted by miR-18b-expression et al. [40] showed that miR-18a is expressed in the tumour cells of $\mathrm{ER}^{+}$breast cancer tissue. These authors also describe that miR-18a is significantly under-expressed in $\mathrm{ER}^{-}$breast cancers, this is in contrast to most studies that report higher expression in $\mathrm{ER}^{-}$breast cancers. There are some technical differences in the CISH protocol between Guo et al. and the current study, and this might explain the differences in level of expression and location. The localisation of miR-18a and miR-18b expression is important in order to understand the role of these microRNAs in $\mathrm{ER}^{-}$breast tumours and in breast cancer progression.

The use of CISH in the current study clearly shows that the expression of miR-18a and miR-18b is located in the stroma of $\mathrm{ER}^{-}$breast cancer with a high number of TILs. Furthermore, in breast cancer patients these microRNAs are also observed in lymph nodes both with and without macroscopically confirmed tumour cells. In lymph nodes from patients without cancer, the miR-18a and $-18 \mathrm{~b}$ positive cells were found only in the germinal centres. Meanwhile, in metastatic lymph nodes of breast cancer patients, miR-18a and $-18 b$ positive cells were found close to the tumour cells, and absent in the germinal centres. These observational results should be considered preliminary, nonetheless they do suggest a potential migration or activation of specific immune cells, related to $\mathrm{ER}^{-}$breast tumour cells. In accordance with the stromal localization of miR$18 \mathrm{a}$ and $-18 \mathrm{~b}$ positive cells demonstrated by CISH and the partial overlap with CD68 staining, CIBERSORT analyses in two different cohorts showed a significant positive correlation between M1 / M0 macrophages and the expression of miR-18a and miR18b. Similarly, Halvorsen et al. showed a correlation between the miR17 92 cluster and CD68 positive cells (i.e. monocytes/macrophages) when investigating 


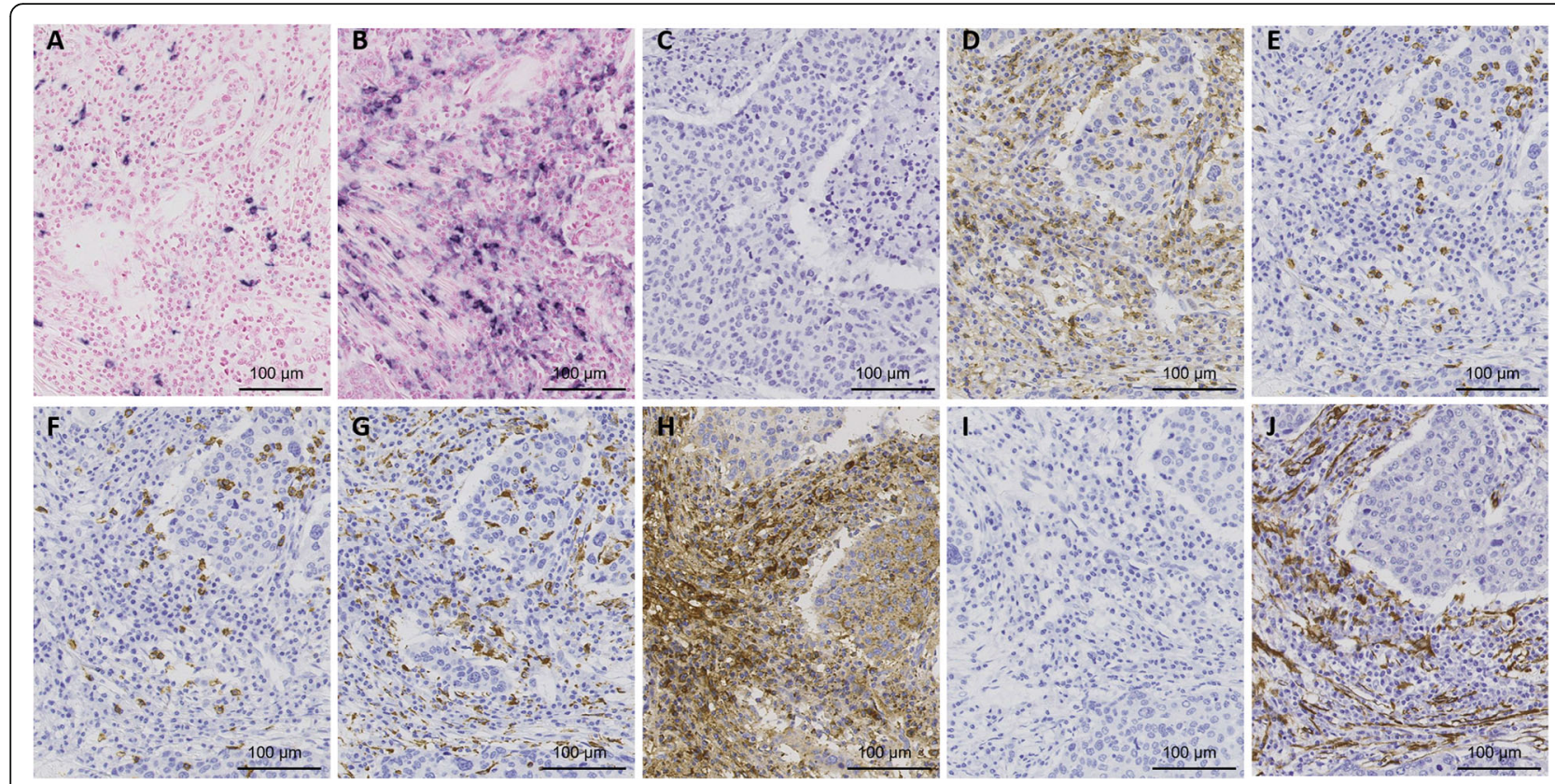

Fig. 5 Expression pattern in an ER' breast tumour (sample id: 13 ER $^{-}$in Table 2) of a) CISH LNA 5'-3'DIG hsa (80 nM) miR-18a probe and b) CISH LNA 5'3'DIG hsa miR-18b (80 nM) probe in comparison to IHC staining for c) ER, d) CD4, e) CD8, f) CD20, g) CD68, h) CD138, i) PAX5 and j) actin. Scale bar $100 \mu \mathrm{m}$

microRNAs isolated from the tumour interstitial fluid from breast cancer patients [21].

Interestingly, together with several other microRNAs, miR-18b has been suggested to play an important part in macrophage lineage development, through regulation of important macrophage transcription factors such as PU.1, RUNX1, CSFR1, PPAR $\alpha$ and PPAR $\gamma$ [41]. As such, one might stipulate that overexpression of miR-18b might lead to increased expression of cytokines such as IL1 $\beta$, IL-6 and TNF $\alpha$, thereby increasing a pro-

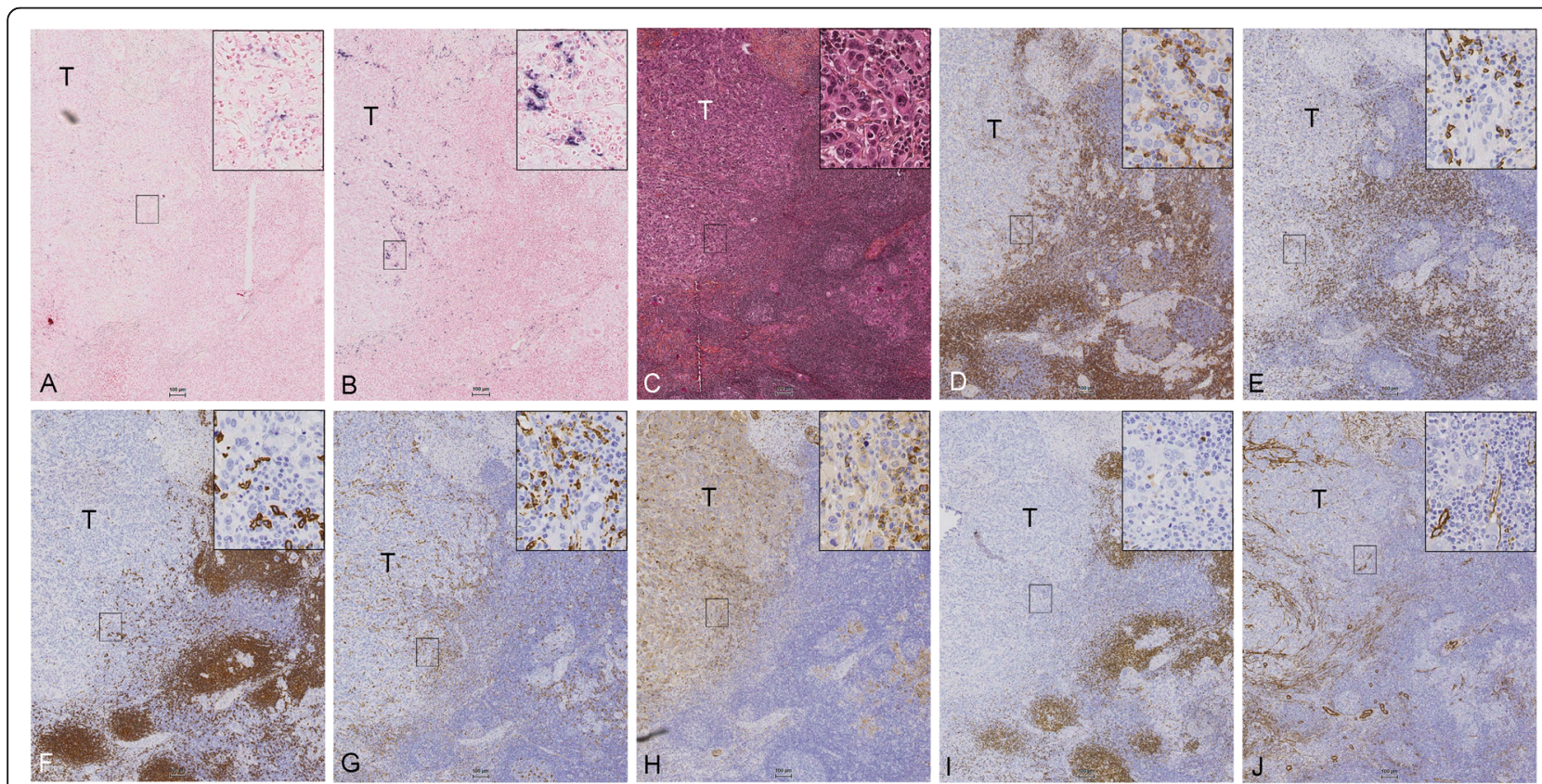

Fig. 6 Expression pattern comparison in a lymph node with tumour infiltration from a patient with an ER ${ }^{-}$breast tumour. a) CISH LNA 5'-3'DIG hsa (80 nM) miR-18a probe and b) CISH LNA 5'-3'DIG hsa ( $80 \mathrm{nM}$ ) miR-18b probe, in comparison to $\mathrm{IHC}$ staining for $\mathbf{c}$ ) HE, and IHC-staining for d) CD4, e) CD8, f) CD20, g) CD68, h) CD138, i) PAX5, and j) actin. T indicates tumour area. Scale bar $100 \mu \mathrm{m}$ 


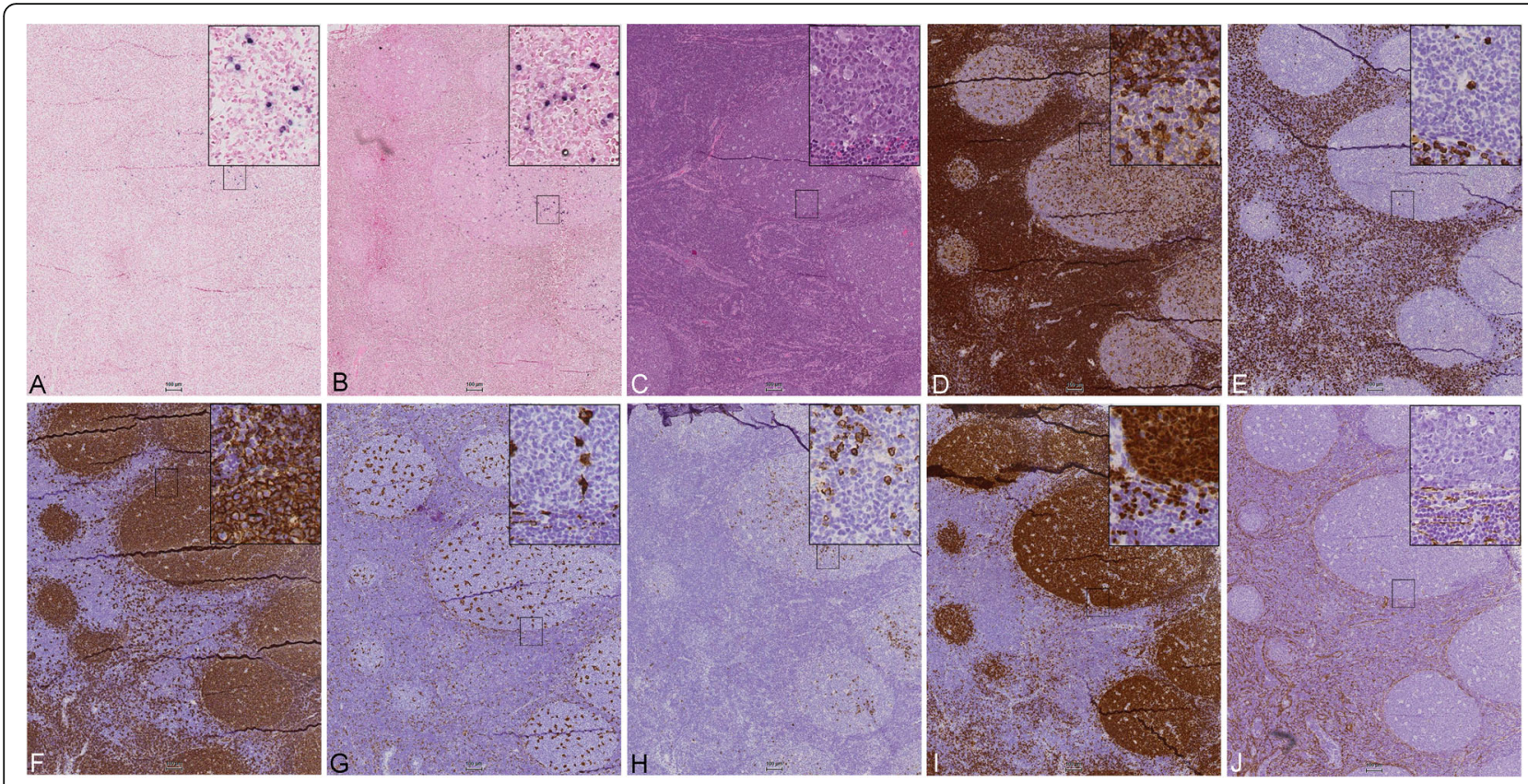

Fig. 7 Expression pattern comparison in a benign lymph node diagnosed as reactive lymphadenitis from the neck. a) CISH LNA 5'-3'DIG hsa (80 nM) miR-18a probe and b) CISH LNA 5'-3'DIG hsa (80 nM) miR-18b probe, in comparison to IHC staining for c) HE, and IHC-staining for d) CD4, e) CD8, f) CD20, g) CD68, h) CD138, i) PAX5, and j) actin. Scale bar $100 \mu \mathrm{m}$

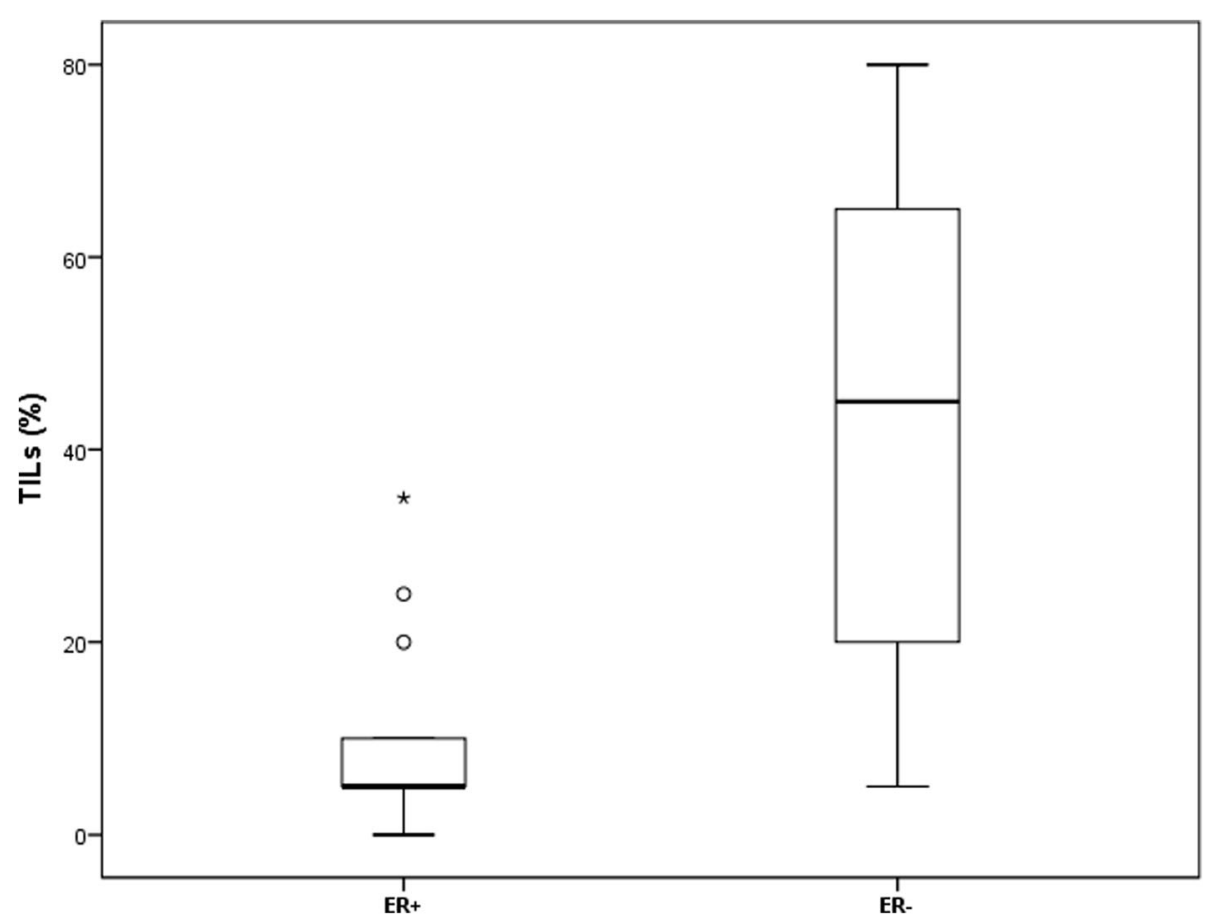

Fig. 8 Boxplot of TILs quantification, as measured by scoring the \% of tumor-infiltrating lymphocytes in the $n=20 E R^{+}$vs the $n=20 E R^{-}$breast cancers in the $\mathrm{CISH}$-cohort. Central line in boxes represent the median value, boundaries of boxes represent the interquartile range and ends of whiskers represent the minimum and maximum values, excluding outliers 
Table 3 CIBERSORT analyses, Stavanger array cohort and Oslo2 cohort

\begin{tabular}{|c|c|c|c|c|c|c|c|c|c|}
\hline \multicolumn{5}{|l|}{ Stavanger array cohort $(n=94)$} & \multicolumn{5}{|l|}{ Oslo2 cohort $(n=377)$} \\
\hline & \multicolumn{2}{|c|}{ hsa-miR-18a } & \multicolumn{2}{|c|}{ hsa-miR-18b } & & \multicolumn{2}{|c|}{ hsa-miR-18a } & \multicolumn{2}{|c|}{ hsa-miR-18b } \\
\hline & Corr. $^{a}$ & $P$ & Corr. $^{a}$ & $P$ & & Corr. $^{a}$ & $P$ & Corr. ${ }^{\text {a }}$ & $P$ \\
\hline M1 Macrophages & 0.415 & 0.001 & 0.387 & 0.001 & Memory activated CD4+ T-cells & 0.265 & 0.001 & 0.303 & 0.001 \\
\hline Memory activated CD4+ T-cells & 0.328 & 0.001 & 0.308 & 0.002 & Activated Dendritic cells & 0.245 & 0.001 & 0.242 & 0.001 \\
\hline MO Macrophages & 0.299 & 0.003 & 0.279 & 0.006 & M1 Macrophages & 0.241 & 0.001 & 0.286 & 0.001 \\
\hline Monocytes & 0.159 & 0.125 & 0.157 & 0.132 & Neutrophils & 0.177 & 0.001 & 0.151 & 0.003 \\
\hline
\end{tabular}

List of the top four immune cells that correlate with miR-18a and miR-18b expression. ${ }^{a}$ indicates Absolute Spearman's Rho correlation

inflammatory condition in the TME. Additionally, miR$18 \mathrm{a}-5 \mathrm{p}$ can promote carcinogenesis by directly targeting interferon regulatory factor 2 (IRF2) [42]. IRF2 is a member of the IRF family, which has the ability to exert anti-oncogenic activities; others showed that IRF2 is an important regulator of the pro-inflammatory response in macrophages by controlling HIF- $1 \alpha$-dependent glycolytic gene expression and glycolysis [43]. Interestingly, miR-18a has also been identified as an upstream regulator of hypoxia-inducible factor $1 \alpha$ (HIF1A) [44, 45]. HIF1A is associated with macrophage function, whereby its overexpression induces macrophage M1 polarization [46], and it also plays a role in centrosome aberrations and tumour progression in TNP breast cancer [47].

CIBERSORT analyses in two independent cohorts resulted in a positive miR-18a and $-18 \mathrm{~b}$ correlation with CD4+ T-cell memory cells; a subset of T-cells that can recognize foreign invaders such as bacteria or viruses, as well as cancer cells. Vahidi et al. [48] recently studied different subtypes of memory T-cells in the CD4+ population in tumour draining lymph nodes of 52 untreated breast cancer patients. Among all the CD4+ memory Tcells, more than $70 \%$ of the cells exhibited a memory phenotype, and in the tumour positive lymph nodes the frequency of $\mathrm{T}$ stem cell memory cells was higher than in tumour negative lymph nodes [48]. Jiang et al. studied the role of the miR-17 $\sim 92$ cluster during the T-cell antigen response and showed that miR-18a counteracts other microRNAs (e.g. miR-17 and miR-19 display a pro-Th1 function) by inhibition of proliferation and an increase in activation-induced cell death of $\mathrm{CD} 4+\mathrm{T}$ cells [49].

Both we and others have shown that miR-18a and miR-18b are related to $E R^{-}$tumours, and several studies have shown that both miR-18a and miR-18b directly repress ER activity $[13-15,17,50,51]$ and thus direct the location of these microRNA to the cancer cells.

It has also been demonstrated that microRNAs have the ability to take part in crosstalk between tumour cells and the microenvironment, by exosomal delivery $[25,26]$. From different cancer studies circulating miR-18a has been detected as a potential microRNA biomarker for early detection of cancer in serum samples [52, 53].
Meanwhile, analysis of serum samples from 60 breast cancer patients with triple-negative tumours showed that miR-18b has prognostic value for distant metastases and overall survival [39]. These results show that miR-18a and -18b could be detected in liquid biopsies, and might therefore be potential biomarkers for tumour progression and worse prognosis in breast cancer.

The IHC staining performed and presented in the current study does not show a complete overlap with miR-18a and miR-18b (Table 1). Still, the finding of expression of these microRNAs in both elongated and smaller round cells could fit with expression in both macrophages and T-cells. A combination of both IHC and CISH on the same slide, or staining with several antibodies simultaneously, might be an appropriate way to improve the identification of the proper cell type(s) expressing these microRNAs.

Based on existing literature (cited above) and our studies, we can only conclude that miR-18a and miR-18b appears to be highly expressed among TILs in $\mathrm{ER}^{-}$breast cancer, and that the expression of these microRNAs is correlated with a worse prognosis in these patients. While miR-18a and -18b might be linked to macrophages and memory T-cells, we speculate that these cells are not effective enough to stop the tumours from forming metastases.

There are some limitations to this study; first of all, we have only evaluated 40 patients with the CISH method. Second, the in situ expression of miR-18a and -18b did not show a complete overlap with any of the IHC markers. Third, although the CIBERSORT results were significant in two independent cohorts, this data shows only an association between the miR-18a and miR-18b expression and the different immune cells. These results should therefore be interpreted with caution. The exact function of these microRNAs in breast cancer stromal tissue, what type of cells express them, and how they relate to the infiltration of immune cells such as macrophages, needs further investigation.

\section{Conclusions}

In conclusion, our results show that miR-18a and miR$18 \mathrm{~b}$ are highly expressed in the stromal compartment 
adjacent to $\mathrm{ER}^{-}$tumour cells, especially in areas containing a high degree of infiltrating lymphocytes. The expression of miR-18a and miR-18b is positively correlated with the presence of macrophages and CD4 memory $\mathrm{T}$ cells. We hypothesize that the expression of these microRNAs is related to a systemic immunological response, possibly produced by monocytes/macrophages that are activated in lymph nodes, and thereafter homed towards specific tumours. Further investigation in larger patient cohorts is needed to validate these miR-18a and miR$18 \mathrm{~b}$-expressing stromal cells as macrophages.

\section{Supplementary information}

Supplementary information accompanies this paper at https://doi.org/10. 1186/s12885-020-06857-7.

Additional file 1: S1 Table. Patient characteristics in the CISH cohort.

Additional File 2: S2 Table. Name, sequence, RNA Tm and

concentration for the LNA ${ }^{T M} 5^{\prime}-3^{\prime}$ DIG hsa detection probes (Exiqon) used in $\mathrm{CISH}$ experiments.

Additional file 3: S1 Fig. miR-18b expression in primary tumour corresponding to Fig. 6. Positive and specific CISH expression of LNA 5'3'DIG miR-18b (80 nM) in the stroma of a representative lymph nodepositive primary breast cancer tumour.

Additional file 4: S2 Fig. Expression pattern comparison in a lymph node with tumour infiltration from a patient with an $E R^{+}$breast tumour. A) CISH LNA 5 '-3'DIG hsa (80 nM) miR-18a probe and B) CISH LNA 5'$3^{\prime} \mathrm{DIG}$ hsa (80 nM) miR-18b probe, in comparison to IHC staining for C) $\mathrm{HE}$, and $\mathrm{IHC}$-staining for D) CD4, E) CD8, F) CD20, G) (D68, H) CD138, I) PAX5, and J) actin.

Additional file 5: S3 Fig. Expression measured with $\mathrm{qPCR}$ in $\mathrm{ER}^{+}$and $E R^{-}$breast cancers with high and low TILs of A) miR-18a and B) miR-18b. Central line in boxes represent the median value, boundaries of boxes represent the interquartile range and ends of whiskers represent the minimum and maximum values, excluding outlies. P-values were obtained using independent T-test.

Additional file 6: S4 Fig. CISH expression demonstrating strong and specific positive staining with LNA 5'-3'DIG hsa ( $80 \mathrm{nM}$ ) miR-18b probe expression in A) pancreatic cancer, and B) lung cancer.

\section{Abbreviations}

ER: Oestrogen receptor alpha; TME: Tumour microenvironment; FFPE: Formalin fixed paraffin embedded; CISH: Chromogenic in situ hybridization; TILs: Tumour infiltrating lymphocytes; TAM: Tumour associated macrophages; IHC: Immunohistochemistry; qPCR: Quantitative real-time PCR; PR: Progesterone receptor; HER2: Human epidermal growth factor receptor 2; TNP: Triple-negative phenotype

\section{Acknowledgements}

We thank Bianca van Diermen-Hidle, Marit Nordhus and Melinda Lillesand for their excellent technical assistance. We thank Jörn Schulz for valuable help with statistical analyses. We acknowledge OSBREAC (Oslo Breast Cancer Research Consortium) for the Oslo2 data.

\section{Authors' contributions}

EAMJ and $\mathrm{KJ}$ conceived and designed the study. $\mathrm{KJ}$ and IS contributed to the experimental design of CISH. NGE optimized the CISH protocol and performed the CISH experiments. EAMJ and NGE quantified the microRNAs and scored the lymphocyte infiltration. EAMJ, KJ, IS, EG and NGE analysed and interpreted the $\mathrm{CISH} / \mathrm{TILS} / \mathrm{IHC}$ results and images. EG provided clinical input. MRA, KS and VNK provided the Oslo2 data. KJ performed the statistical analyses in SPSS. MRA performed and analysed the CIBERSORT analyses. DCF, JPAB, MRA, KS and VNK provided intellectual and critical input MRA, KS, VNK DCF and EAMJ contributed to interpretation of the results and critically revised the manuscript. EAMJ and $\mathrm{KJ}$ overviewed and coordinated the study. NGE and KJ made the figures and tables and wrote the manuscript. All authors reviewed and approved the final version of the manuscript. $\mathrm{KJ}$ and NGE contributed equally to this work.

\section{Funding}

Kristin Jonsdottir and Nina Gran Egeland obtained a grant from Folke Hermansen Foundation (2013 and 2014), Norway, and the study received financial support from the Western Norway Health Authority (grant number 911790) and the Stavanger University Hospital research department (20092010). Miriam Ragle Aure is a postdoctoral fellow of the South Eastern Norway Health Authority (grant number 2014021). Deirdre Cronin-Fenton obtained a grant from the Danish Cancer Research Foundation. The funding bodies had no role in study design, collection, analysis, interpretation of data, writing the manuscript or decision to publish.

\section{Availability of data and materials}

The mRNA dataset for the Stavanger array cohort is publicly available at the online Gene Expression Omnibus (GEO) repository: accession number GSE46563. The Oslo2 microRNA expression data are available from the GEO repository with accession number GSE58210, while the mRNA expression data has accession number GSE58212. Additional datasets used and/or analysed during the current study are available from the corresponding author on reasonable request.

\section{Ethics approval and consent to participate}

This study was approved by the Regional Committees for Medical and Health Research Ethics (REC), part of the Norwegian National Research Ethics Committees. The Stavanger cohort was approved by REC Region West, approval number 2010/2014. As this is a retrospective study, approval was given without written consent from the patients. All insights in a patient's journal were monitored electronically, and all except the treating physician were required to state the reason why they needed to read that patient's journal. This log was always open for the patient to view. The Oslo2 cohort was approved by REC Region South East, approval number 2016/433 and 429-04148. These patients were included at the time of primary surgery after giving written informed consent.

\section{Consent for publication}

Not applicable.

\section{Competing interests}

None of the authors have any financial or other relationships with entities that have investment, licensing, or other commercial interests in the subject matter under consideration in this article.

\section{Author details}

${ }^{1}$ Department of Pathology, Stavanger University Hospital, Box 8100, 4068 Stavanger, Norway. ${ }^{2}$ Department of Chemistry, Bioscience and Environmental Engineering, University of Stavanger, Stavanger, Norway. ${ }^{3}$ Department of Cancer Genetics, Institute for Cancer Research, Oslo University Hospital, Oslo, Norway. ${ }^{4}$ Department of Research and Innovation, Vestre Viken Hospital Trust, Drammen, Norway. ${ }^{5}$ Department of Clinical Molecular Biology (EpiGen), Division of Medicine, Akershus University Hospital, Lørenskog, Norway. ${ }^{6}$ Department of Clinical Epidemiology, Aarhus University, Aarhus, Denmark.

${ }^{7}$ Dr. Med. Jan Baak AS, Tananger, Norway.

Received: 26 September 2019 Accepted: 13 April 2020

Published online: 05 May 2020

\section{References}

1. Foulkes WD, Smith IE, Reis-Filho JS. Triple-negative breast cancer. N Engl J Med. 2010;363(20):1938-48.

2. Norway CRo. National Quality Registry for Breast Cancer, 2017 Yearly report. Oslo2018. Available from: https://www.kreftregisteret.no/globalassets/ publikasjoner-og-rapporter/arsrapporter/publisert-2018/arsrapport-2017brystkreft.pdf. Accessed 01 Apr 2019.

3. Guo H, Ingolia NT, Weissman JS, Bartel DP. Mammalian microRNAs predominantly act to decrease target mRNA levels. Nature. 2010;466(7308): 835-40. 
4. Lewis BP, Burge CB, Bartel DP. Conserved seed pairing, often flanked by adenosines, indicates that thousands of human genes are microRNA targets. Cell. 2005;120(1):15-20.

5. Alvarez-Garcia I, Miska EA. MicroRNA functions in animal development and human disease. Development. 2005;132(21):4653-62.

6. Lu M, Zhang Q, Deng M, Miao J, Guo Y, Gao W, et al. An analysis of human microRNA and disease associations. PLoS One. 2008;3(10):e3420.

7. Li Y, Qiu C, Tu J, Geng B, Yang J, Jiang T, et al. HMDD v2.0: a database for experimentally supported human microRNA and disease associations. Nucleic Acids Res. 2014;42(Database issue):D1070-4.

8. Jonsdottir K, Janssen SR, Da Rosa FC, Gudlaugsson E, Skaland I, Baak JP, et al. Validation of expression patterns for nine miRNAs in 204 lymph-node negative breast cancers. PLoS One. 2012;7(11):e48692.

9. Janssen EA, Slewa A, Gudlaugsson E, Jonsdottir K, Skaland I, Soiland H, et al. Biologic profiling of lymph node negative breast cancers by means of microRNA expression. Modern pathology : an official journal of the United States and Canadian Academy of Pathology, Inc. 2010;23(12):1567-76.

10. Mogilyansky E, Rigoutsos I. The miR-17/92 cluster: a comprehensive update on its genomics, genetics, functions and increasingly important and numerous roles in health and disease. Cell Death Differ. 2013;20(12):1603-14.

11. Olive V, Jiang I, He L. Mir-17-92, a cluster of miRNAs in the midst of the cancer network. Int J Biochem Cell Biol. 2010;42(8):1348-54.

12. He L, Thomson JM, Hemann MT, Hernando-Monge E, Mu D, Goodson S, et al. A microRNA polycistron as a potential human oncogene. Nature. 2005; 435(7043):828-33.

13. Leivonen SK, Makela R, Ostling P, Kohonen P, Haapa-Paananen S, Kleivi K, et al. Protein lysate microarray analysis to identify microRNAs regulating estrogen receptor signaling in breast cancer cell lines. Oncogene. 2009; 28(44):3926-36.

14. Fonseca-Sanchez MA, Perez-Plasencia C, Fernandez-Retana J, ArechagaOcampo E, Marchat LA, Rodriguez-Cuevas S, et al. microRNA-18b is upregulated in breast cancer and modulates genes involved in cell migration. Oncol Rep. 2013;30(5):2399-410.

15. Enerly E, Steinfeld I, Kleivi K, Leivonen SK, Aure MR, Russnes HG, et al. miRNA-mRNA integrated analysis reveals roles for miRNAs in primary breast tumors. PloS one. 2011:6(2):e16915.

16. Castellano L, Giamas G, Jacob J, Coombes RC, Lucchesi W, Thiruchelvam P, et al. The estrogen receptor-alpha-induced microRNA signature regulates itself and its transcriptional response. Proc Natl Acad Sci U S A. 2009;106(37):15732-7.

17. Loven J, Zinin N, Wahlstrom T, Muller I, Brodin P, Fredlund E, et al. MYCNregulated microRNAs repress estrogen receptor-alpha (ESR1) expression and neuronal differentiation in human neuroblastoma. Proc Natl Acad Sci U S A. 2010;107(4):1553-8.

18. Quail DF, Joyce JA. Microenvironmental regulation of tumor progression and metastasis. Nat Med. 2013;19(11):1423-37.

19. Bussard KM, Mutkus L, Stumpf K, Gomez-Manzano C, Marini FC. Tumorassociated stromal cells as key contributors to the tumor microenvironment. Breast Cancer Res. 2016;18(1):84.

20. Wang Z, Tan Y, Yu W, Zheng S, Zhang S, Sun L, et al. Small role with big impact: miRNAs as communicators in the cross-talk between cancerassociated fibroblasts and cancer cells. Int J Biol Sci. 2017:13(3):339-48

21. Halvorsen AR, Helland A, Gromov P, Wielenga VT, Talman MM, Brunner N, et al. Profiling of microRNAs in tumor interstitial fluid of breast tumors - a novel resource to identify biomarkers for prognostic classification and detection of cancer. Mol Oncol. 2017:11(2):220-34.

22. Shah SH, Miller P, Garcia-Contreras M, Ao Z, Machlin L, Issa E, et al. Hierarchical paracrine interaction of breast cancer associated fibroblasts with cancer cells via hMAPK-microRNAs to drive ER-negative breast cancer phenotype. Cancer biology \& therapy. 2015;16(11):1671-81.

23. Bayraktar R, Van Roosbroeck K, Calin GA. Cell-to-cell communication: microRNAs as hormones. Mol Oncol. 2017;11(12):1673-86.

24. Penfornis $P$, Vallabhaneni $K C$, Whitt J, Pochampally R. Extracellular vesicles as carriers of microRNA, proteins and lipids in tumor microenvironment. International journal of cancer Journal international du cancer. 2016;138(1): 14-21.

25. Valadi H, Ekstrom K, Bossios A, Sjostrand M, Lee JJ, Lotvall JO. Exosomemediated transfer of mRNAs and microRNAs is a novel mechanism of genetic exchange between cells. Nat Cell Biol. 2007;9(6):654-9.

26. Zheng P, Chen L, Yuan X, Luo Q, Liu Y, Xie G, et al. Exosomal transfer of tumor-associated macrophage-derived miR-21 confers cisplatin resistance in gastric cancer cells. J Exp Clin Cancer Res. 2017;36(1):53.
27. Sakai T, Aokage K, Neri S, Nakamura H, Nomura S, Tane K, et al. Link between tumor-promoting fibrous microenvironment and an immunosuppressive microenvironment in stage I lung adenocarcinoma. Lung cancer (Amsterdam, Netherlands). 2018;126:64-71.

28. Lanca T, Silva-Santos B. The split nature of tumor-infiltrating leukocytes: implications for cancer surveillance and immunotherapy. Oncoimmunology. 2012;1(5):717-25.

29. Stanton SE, Disis ML. Clinical significance of tumor-infiltrating lymphocytes in breast cancer. J Immunother Cancer. 2016;4(1):59.

30. Newman AM, Liu CL, Green MR, Gentles AJ, Feng W, Xu Y, et al. Robust enumeration of cell subsets from tissue expression profiles. Nat Methods. 2015;12(5):453-7.

31. Jonsdottir K, Assmus J, Slewa A, Gudlaugsson E, Skaland I, Baak JP, et al. Prognostic value of gene signatures and proliferation in lymph-nodenegative breast cancer. PLoS One. 2014:9(3):e90642.

32. Aure MR, Jernstrom S, Krohn M, Vollan HK, Due EU, Rodland E, et al. Integrated analysis reveals microRNA networks coordinately expressed with key proteins in breast cancer. Genome Med. 2015;7(1):21.

33. Aure MR, Vitelli V, Jernstrom S, Kumar S, Krohn M, Due EU, et al. Integrative clustering reveals a novel split in the luminal a subtype of breast cancer with impact on outcome. Breast Cancer Res. 2017;19(1):44.

34. Tavassoli FA, Devilee P. WHO classification of Tumours. Pathology and genetics of Tumours of the breast and female genital organs. Lyon: IARC Press; 2003.

35. Elston CW, Ellis IO. Pathological prognostic factors in breast cancer. I. the value of histological grade in breast cancer: experience from a large study with long-term follow-up. Histopathology. 1991;19(5):403-10.

36. Jonsdottir K, Zhang H, Jhagroe D, Skaland I, Slewa A, Bjorkblom B, et al. The prognostic value of MARCKS-like 1 in lymph node-negative breast cancer. Breast Cancer Res Treat. 2012;135(2):381-90.

37. Denkert C, Loibl S, Noske A, Roller M, Muller BM, Komor M, et al. Tumorassociated lymphocytes as an independent predictor of response to neoadjuvant chemotherapy in breast cancer. J Clin Oncol. 2010;28(1): $105-13$.

38. R Core Team. R Core team. R: a language and environment for statistical computing. Vienna: R Foundation for statistical Computing; 2018.

39. Kleivi Sahlberg K, Bottai G, Naume B, Burwinkel B, Calin GA, Borresen-Dale $A L$, et al. A serum microRNA signature predicts tumor relapse and survival in triple-negative breast cancer patients. Clin Cancer Res. 2015;21(5): 1207-14.

40. Guo X, Yang C, Qian X, Lei T, Li Y, Shen H, et al. Estrogen receptor alpha regulates ATM expression through miRNAs in breast cancer. Clin Cancer Res. 2013;19(18):4994-5002.

41. Zhou H, Zhang J, Eyers F, Xiang Y, Herbert C, Tay HL, et al. Identification of the microRNA networks contributing to macrophage differentiation and function. Oncotarget. 2016;7(20):28806-20.

42. Liang C, Zhang X, Wang HM, Liu XM, Zhang XJ, Zheng B, et al. MicroRNA$18 a-5 p$ functions as an oncogene by directly targeting IRF2 in lung cancer. Cell Death Dis. 2017:8(5):e2764.

43. Cui H, Banerjee S, Guo S, Xie N, Liu G. IFN regulatory factor 2 inhibits expression of glycolytic genes and lipopolysaccharide-induced Proinflammatory responses in macrophages. J Immunol. 2018;200(9): 3218-30.

44. Krutilina R, Sun W, Sethuraman A, Brown M, Seagroves TN, Pfeffer LM, et al. MicroRNA-18a inhibits hypoxia-inducible factor 1alpha activity and lung metastasis in basal breast cancers. Breast Cancer Res. 2014;16(4):R78.

45. Han F, Wu Y, Jiang W. MicroRNA-18a decreases Choroidal endothelial cell proliferation and migration by inhibiting HIF1A expression. Med Sci Monitor. 2015:21:1642-7.

46. Wang T, Liu H, Lian G, Zhang SY, Wang X, Jiang C. HIF1alpha-induced glycolysis metabolism is essential to the activation of inflammatory macrophages. Mediat Inflamm. 2017;2017:9029327.

47. Mittal K, Choi DH, Ogden A, Donthamsetty S, Melton BD, Gupta MV, et al. Amplified centrosomes and mitotic index display poor concordance between patient tumors and cultured cancer cells. Sci Rep. 2017;7:43984.

48. Vahidi Y, Faghih Z, Talei AR, Doroudchi M, Ghaderi A. Memory CD4(+) T cell subsets in tumor draining lymph nodes of breast cancer patients: a focus on T stem cell memory cells. Cellular Oncol. 2018:41(1):1-11.

49. Jiang S, Li C, Olive V, Lykken E, Feng F, Sevilla J, et al. Molecular dissection of the miR-17-92 cluster's critical dual roles in promoting Th1 responses and preventing inducible Treg differentiation. Blood. 2011;118(20):5487-97. 
50. Yoshimoto N, Toyama T, Takahashi S, Sugiura H, Endo Y, Iwasa M, et al. Distinct expressions of microRNAs that directly target estrogen receptor alpha in human breast cancer. Breast Cancer Res Treat. 2011;130(1):331-9.

51. Calvano Filho CM, Calvano-Mendes DC, Carvalho KC, Maciel GA, Ricci MD, Torres AP, et al. Triple-negative and luminal a breast tumors: differential expression of miR-18a-5p, miR-17-5p, and miR-20a-5p. Tumour Biol. 2014; 35(8):7733-41.

52. Kodahl AR, Lyng MB, Binder H, Cold S, Gravgaard K, Knoop AS, et al. Novel circulating microRNA signature as a potential non-invasive multi-marker test in ER-positive early-stage breast cancer: a case control study. Mol Oncol. 2014;8(5):874-83.

53. Komatsu S, Ichikawa D, Takeshita H, Morimura R, Hirajima S, Tsujiura M, et al. Circulating miR-18a: a sensitive cancer screening biomarker in human cancer. In vivo (Athens, Greece). 2014;28(3):293-7.

\section{Publisher's Note}

Springer Nature remains neutral with regard to jurisdictional claims in published maps and institutional affiliations.

Ready to submit your research? Choose BMC and benefit from:

- fast, convenient online submission

- thorough peer review by experienced researchers in your field

- rapid publication on acceptance

- support for research data, including large and complex data types

- gold Open Access which fosters wider collaboration and increased citations

- maximum visibility for your research: over $100 \mathrm{M}$ website views per year

At $\mathrm{BMC}$, research is always in progress.

Learn more biomedcentral.com/submissions 